\title{
The Temporal Sequence and the Differences in Somatic Mutation Acquisition Determines Clinical Behaviors of JAK2-Positive Myeloproliferative Neoplasms
}

\author{
JA MIN BYUN ${ }^{1}$, SEULKI SONG ${ }^{2}$, YOUNGIL KOH ${ }^{1}$, SUNG-SOO YOON $^{1,2}$ and DAEYOON KIM ${ }^{2}$ \\ ${ }^{1}$ Department of Internal Medicine, Seoul National University College of Medicine, \\ Seoul National University Hospital, Seoul, Republic of Korea; \\ ${ }^{2}$ Cancer Research Institute, Seoul National University Hospital, Seoul, Republic of Korea
}

\begin{abstract}
Background/Aim: We have yet to understand why JAK2-positive myeloproliferative neoplasms (MPN) patients manifest different phenotypes despite harboring JAK2 mutations and what drives secondary transformations. Patients and Methods: Using targeted sequencing, we analyzed mutational status of 17 polycythemia vera $(P V), 16$ essential thrombocythemia (ET), 8 primary myelofibrosis (PMF) patients who tested positive for JAK by polymerase chain reaction. Results: The somatic mutations in JAK2 influence the clinical behavior of the disease. We found that ASXL1 or EZH2 mutation acquisition after JAK2 leads to PV, while ASXL1 mutation acquisition before JAK2 leads to ET or PMF. Mutations in TP53, ASXL1, and splicing genes are associated with the prognosis of MPN. PMF was more frequently associated with splicing mutations, while PV was more closely related to mutations in chromatin modifiers. The presence of these mutations influenced hemogram at MPN diagnosis. Conclusion: Each subtype of MPN harbors distinct patterns of somatic mutations and acquisition order, while mutations in TP53, ASXL1, and splicing genes may be associated with the prognosis of MPN.
\end{abstract}

Polycythemia vera (PV), essential thrombocythemia (ET), and primary myelofibrosis (PMF) comprise the three major subgroups of $B C R-A B L 1$ negative myeloproliferative

Correspondence to: Sung-Soo Yoon, MD, Ph.D., Department of Internal Medicine, Seoul National University Hospital, 101, Daehak-ro, Jongro-gu, Seoul 03080, Republic of Korea. Tel: +82 220723079, Fax: +82 27629662, e-mail: ssysmc@snu.ac.kr; or Youngil Koh, MD, PhD, Department of Internal Medicine, Seoul National University Hospital, 101, Daehak-ro, Jongro-gu, Seoul 03080, Republic of Korea. Tel: +82 220722228, Fax: +82 27629662, e-mail: go01@snu.ac.kr

Key Words: Myeloproliferative neoplasms, target sequencing, secondary transformation, temporal sequence, JAK2. neoplasms (MPN) (1). The discovery of the JAK2 V617F mutation (2) has allowed for development of novel therapeutic agents and has encouraged the efforts towards molecular diagnostics for MPN. Such efforts have provided evidence of clonality and mutational events preceding the acquisition of $J A K 2 \mathrm{~V} 617 \mathrm{~F}$, and of the presence of recurrent mutations in genes distinct from $J A K 2$ including myeloproliferative leukemia virus oncogene (MPL) (3) and calreticulin $(C A L R)(4)$. Despite the better understanding of the disease, however, certain questions remain unanswered. For example, we cannot yet understand why JAK2 positive MPN patients manifest different phenotypes despite harboring JAK2 mutation as a common denominator. Another unsolved issue is the secondary transformations. To this end, we carried out this study to provide a better understanding of the genetic background of JAK2-positive MPN in selected patients.

\section{Patients and Methods}

Patient samples. This study was carried out at Seoul National University Hospital during the period between May 2010 and April 2016. Patients diagnosed with MPN by cytomorphological evaluation of their bone marrow samples according to WHO criteria, negative for $B C R-A B L 1$ fusion as assessed by polymerase chain reaction (PCR) and positive for $J A K 2 V 617 F$ by PCR were deemed eligible for analysis.

Next generation sequencing. A total of 47 target genes providing diagnostic information in myeloid malignancies were selected based on the literature: CALR, MYC, ETV6, CEBPA, MLL, BRCA2, MPL, SETBP1, PTPN11, ARID1A, ARID2, ATM, BCOR, CTNNA1, EPHB1, FANCA, LRP1B, MEN1, KMT2D, MSH2, NF1, PHF6, PTCH1, RB1, SMARCA4, SUZ12, SH2B2, IKZF1, JAK2, NRAS, KRAS, FLT3, CBL, RUNX1, NPM1, TP53, TET2, ASXL1, EZH2, IDH1/2, UTX, DNMT3A, U2AF1, ZRSR2, SF3B1, and SRSF2. Targeted sequencing was performed with a customized design: TruSeq ${ }^{\circledR}$ Custom Amplicon (Illumina, San Diego, CA, USA) using the MiSeq ${ }^{\circledR}$ sequencing platform (Illumina). TruSeq Custom 
Table I. Baseline characteristics of the enrolled patients.

\begin{tabular}{|c|c|c|c|c|}
\hline & Total & PV & ET & PMF \\
\hline Total $(\mathrm{N}, \%)$ & 41 & 17 & 16 & 8 \\
\hline Male $(\mathrm{N}, \%)$ & $19(46.3)$ & $6(35.3)$ & $8(50.0)$ & $5(62.5)$ \\
\hline Age (median, range) & $63(35-79)$ & $66(45-76)$ & $62(35-79)$ & $58(46-66)$ \\
\hline \multicolumn{5}{|c|}{ Laboratory findings at diagnosis (mean, $\pm \mathrm{SD}$ ) } \\
\hline Hemoglobin (g/dl) & $15.0(3.1)$ & $17.5(2.2)$ & $13.9(2.0)$ & $12.1(3.0)$ \\
\hline Platelet $\left(10^{3} / \mu \mathrm{l}\right)$ & $657(466)$ & 489 (279) & $943(542)$ & $439(350)$ \\
\hline WBC $\left(10^{3} / \mu \mathrm{l}\right)$ & $16.8(22.9)$ & $15.8(13.9)$ & $20.2(33.6)$ & $12.5(8.9)$ \\
\hline \multicolumn{5}{|l|}{ IPSS risk group $(\mathrm{N}, \%)$} \\
\hline Low & $14(34.1)$ & NA & NA & $3(37.5)$ \\
\hline Intermediate-1 & $19(46.3)$ & NA & NA & $2(25.0)$ \\
\hline Intermediate-2 & $8(19.5)$ & NA & NA & $3(37.5)$ \\
\hline High & 0 & NA & NA & 0 \\
\hline \multicolumn{5}{|c|}{ D-IPSS risk group $(\mathrm{N}, \%)$} \\
\hline Low & $3(37.4)$ & NA & NA & $3(37.4)$ \\
\hline Intermediate-1 & $4(50.0)$ & NA & NA & $4(50.0)$ \\
\hline Intermediate-2 & $1(12.5)$ & NA & NA & $1(12.5)$ \\
\hline High & 0 & NA & NA & 0 \\
\hline \multicolumn{5}{|c|}{ Secondary transformation $(\mathrm{N}, \%)$} \\
\hline Total & $7(17.1)$ & $3(17.6)$ & $1(6.3)$ & $3(37.5)$ \\
\hline Acute leukemia & 4 & 1 & 0 & 3 \\
\hline Myelofibrosis & 3 & 2 & 1 & NA \\
\hline
\end{tabular}

PV: Polycythemia vera; ET: essential thrombocythemia; PMF: primary myelofibrosis; SD: standard deviation; WBC: white blood count; IPSS: International Prognostic Scoring System; D-IPSS: Dynamic International Prognostic Scoring System; NA: not applicable.

Amplicon is a fully integrated end-to-end amplicon sequencing solution, including online probe design, assay and sequencing. Online probe design was performed by entering into the Design Studio software (Illumina) the 47 genes. Once the design was completed, TruSeq Custom Amplicon kit produced the required targeted amplicons with the necessary adapters and indices for sequencing on the $\mathrm{MiSeq}^{\circledR}$ system without any additional processing. Library preparation and sequencing runs were performed according to the manufacturer's procedure. Quantified libraries were sequenced using the $2 \times 150 \mathrm{bp}$ configuration (300 cycles) and run on V2 sequencing flow cell. The final targeted sequencing panel consisting of 2228 amplicons covering 47 genes was produced. The mean coverage depth was $1056 \mathrm{X}$.

After sequencing reads were produced, raw de-multiplexed reads from the MiSeq ${ }^{\circledR}$ sequencer were aligned to the reference human genome (UCSC build hg19) using the Burrows-Wheeler Aligner (BWA) (5), running in paired-end mode. To ensure a good call quality and to reduce the number of false positives, samples underwent Base Quality Score Recalibration (BQSR), using the Genome Analysis Toolkit (GATK) (6). Putative somatic variant calls were detected with VarScan 2 (7) and subsequently filtered to exclude non-somatic calls, with an allelic fraction less than $1 \%$, or with a read depth less than 10 . Variant calls were annotated with biological information using ANNOVAR (8). Mutations were annotated with the 1000 Genomes project, dbSNP (version 138) and Catalogue of Somatic Mutations in Cancer (COSMIC), version 68. We only focused on mutations with exon-based region and filtered out all synonymous and unknown genes after annotation. The validity of the somatic mutations was checked against the publicly accessible COSMIC v68 database and functional interpretation was performed using SIFT 1.03, PolyPhen 2.0 and ClinVar. Single- nucleotide polymorphisms (SNP) were annotated according to NCBI dbSNP database.

The temporal sequence of mutation acquisition was surmised based on the variant allele frequency (VAF) values. We have inferred the heterogeneity of each samples using the inferHeterogeneity function and validated them with Sciclone $\mathrm{R}$ package. Using a computational method that efficiently identifies the genetic composition of subclones through a variation Bayesian mixture model (VBMM), spatial patterns of tumor evolution were identified. Sciclone and inferHeterogeneity identify the number and content of subclones by analyzing the variant allele frequencies distribution of single nucleotide variants (SNVs) including somatic variations across samples.

Statistical analyses. Differences between groups were assessed using Student's $t$-test or one-way analysis of variance for continuous variables, and Pearson chi-square test for categorical variables, as indicated. The overall survival (OS) and transformation free survival (TFS) curves were estimated using the Kaplan-Meier method. OS was defined as the time from MPN diagnosis to death or the last follow-up. TFS as the duration from the date of diagnosis to disease transformation or death. All data were analyzed using the Statistical Package for the Social Sciences software (IBM ${ }^{\circledR}$ SPSS ${ }^{\circledR}$ Statistics, version 22.0). $p$-Values of $<0.05$ were considered to indicate statistical significance.

Ethics approval and consent to participate. The study was conducted in compliance with all national and international ethical standards for research with humans and for research using radiopharmaceuticals. This study was conducted according to the Declaration of Helsinki and was approved by the institutional review board of Seoul National 


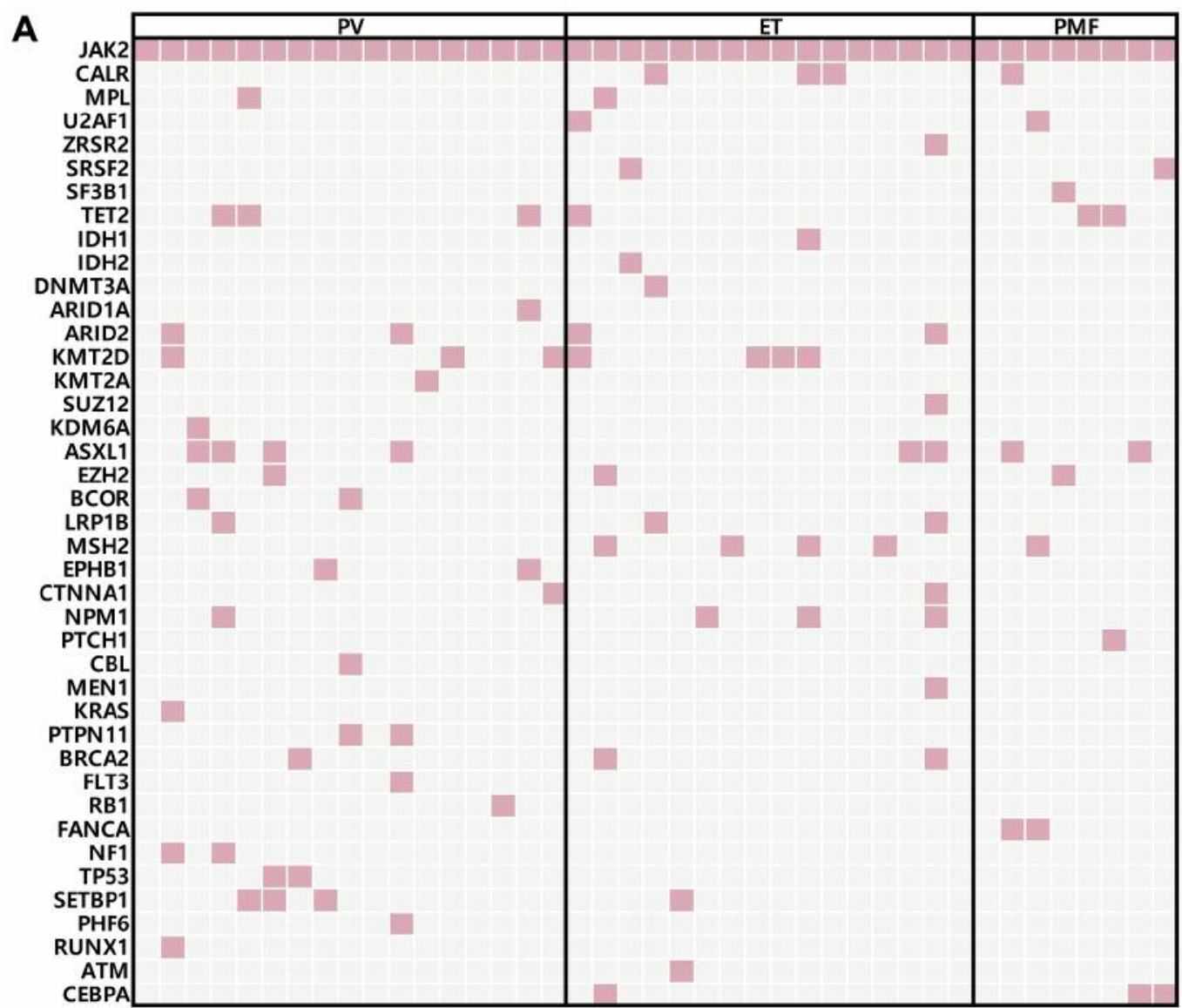

B

$$
12
$$

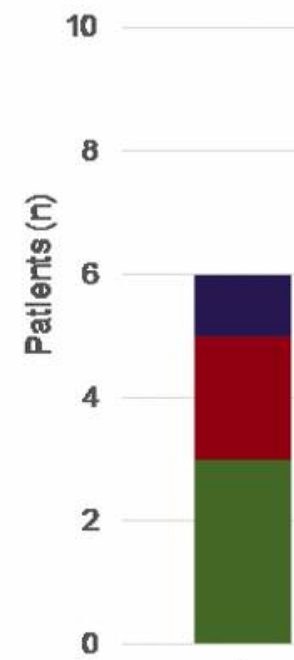

1

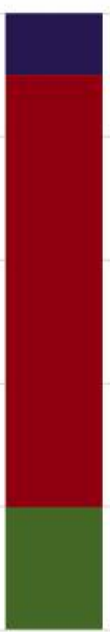

2

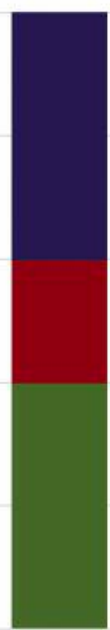

3

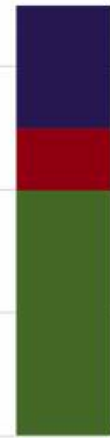

4

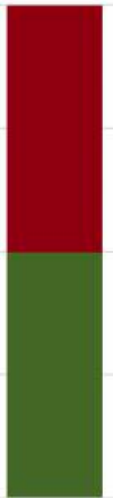

$5+$

Mutated genesipatient

Figure 1. Distribution and frequency of mutations. (A) Distribution of mutated genes is shown on a single sample level. Each column represents one patient sample. PV: Polycythemia vera; ET: essential thrombocythemia; PMF: primary myelofibrosis. (B) Patients were grouped by the number of mutated genes per person. 

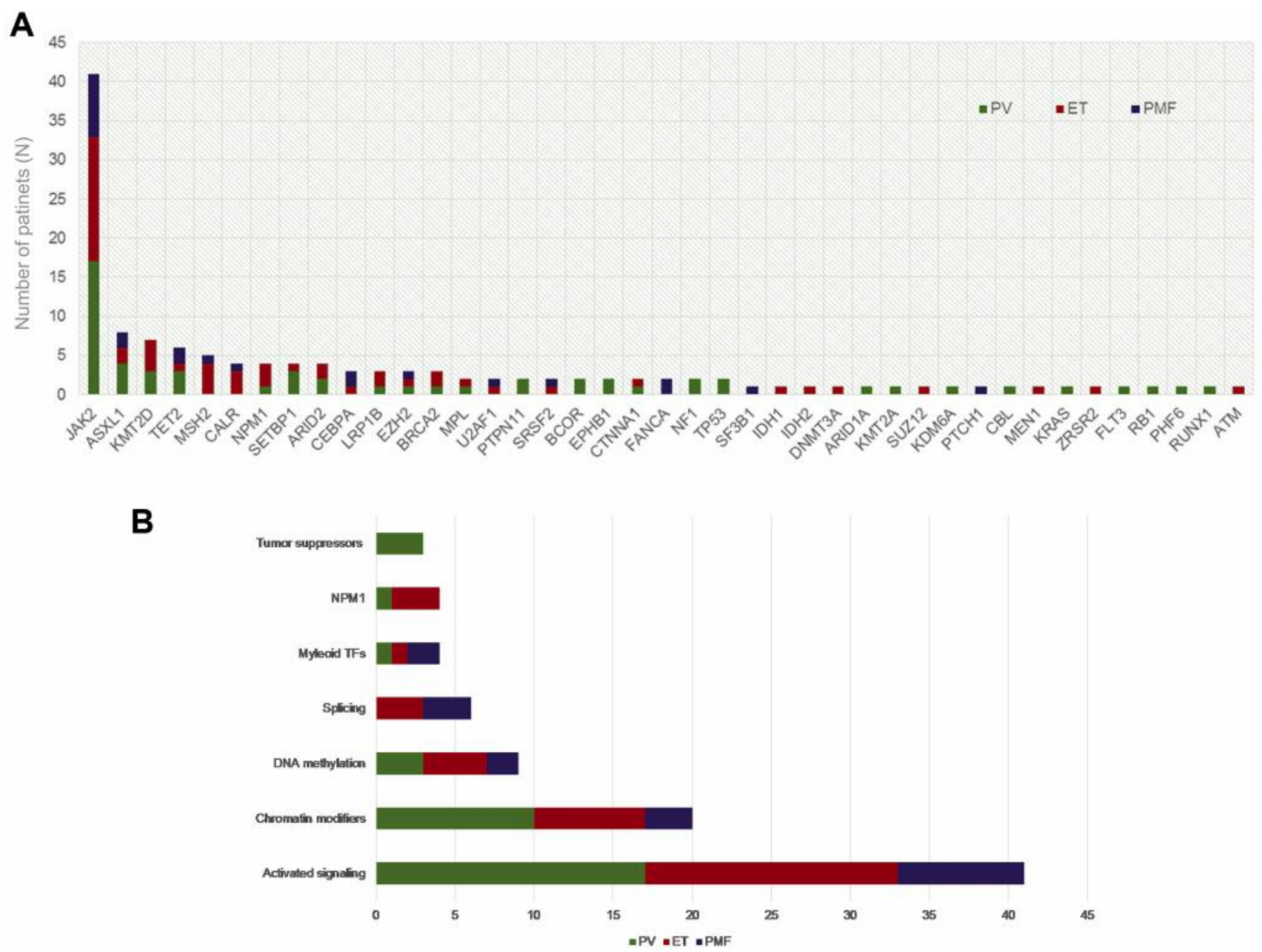

Figure 2. Mutation patterns. (A) Number of patients carrying mutations in the respective genes are shown. (B) Mutated genes grouped by functional pathways. Tumor suppressor genes include TP53 and PHF6; Myeloid TF includes RUNX1 and CEBPA; splicing includes U2AF1, ZRSR2, SRSF2, and SF3B1; DNA methylation includes TET2, IDH1/2, and DNMT3A; Chromatin modifiers include ARID1A, ARID2, KMT2D, KMT2A, SUZ12, KDM6A, ASXL1, EZH2, and BCOR; Activated signaling include JAK2, and KRAS.

University Hospital (IRB No. H-1605-152-768) and patients gave written informed consent before being enrolled.

\section{Results}

Baseline characteristics and distribution of mutations. A total of $41 \mathrm{MPN}$ patients, consisting of $17 \mathrm{PV}, 16 \mathrm{ET}$ and $8 \mathrm{PMF}$, with a median follow-up duration of 39.2 months (range $=1-118$ months) were analyzed for this study (Table I). During followup, 4 secondary leukemias $(9.8 \%)$ and 3 secondary myelofibrosis (sMF) transformations (7.3\%) were documented.

Apart from $J A K 2,8$ genes ASXL1 $(\mathrm{n}=8), K M T 2 D(\mathrm{n}=7)$, TET2 (n=6), MSH2 (n=5), CALR $(\mathrm{n}=4)$, NPM1 $(\mathrm{n}=4)$, SETBP1 $(\mathrm{n}=4)$, ARID2 $(\mathrm{n}=4)$ were mutated in more than $10 \%$ of the analyzed MPN patients (Figures 1A and 2A). As such, when grouped by functional pathways there were many patients harboring mutations in chromatin modification genes (Figure 2B). No mutations were found in the genes ETV6, MYC, SMARCA4, UTY, NRAS and IKZFI.

Subgroup analysis. When the MPN subgroup-specific mutation profiles were analyzed, we found that splicing genes (SF3B1, SRSF2, ZRSR2 and U2AF1) were more frequently mutated in PMF, followed by ET and none in PV patients (Figure 3A). In PMF patients with splicing gene mutation, these splicing mutations seem to occur after JAK2 $V 617 F$ mutation. Also, these patients had significantly higher hemoglobin $($ mean $\pm \mathrm{SD}=14.5 \pm 1.2 v s .10 .5 \pm 2.6 \mathrm{~g} / \mathrm{dl}, p=0.035)$ and platelet $($ mean $\pm \mathrm{SD}=717.2 \pm 275.6$ vs. $260.5 \pm 248.4$ $\left.\times 10^{3} / \mu 1, p=0.049\right)$ count at MPN diagnosis compared to those without splicing mutations (Table II). 
A

0.5

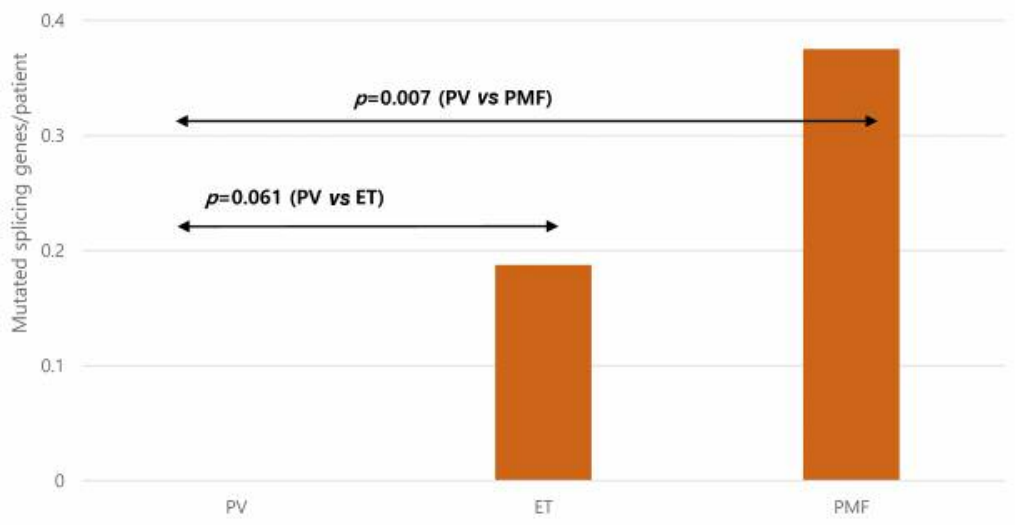

B

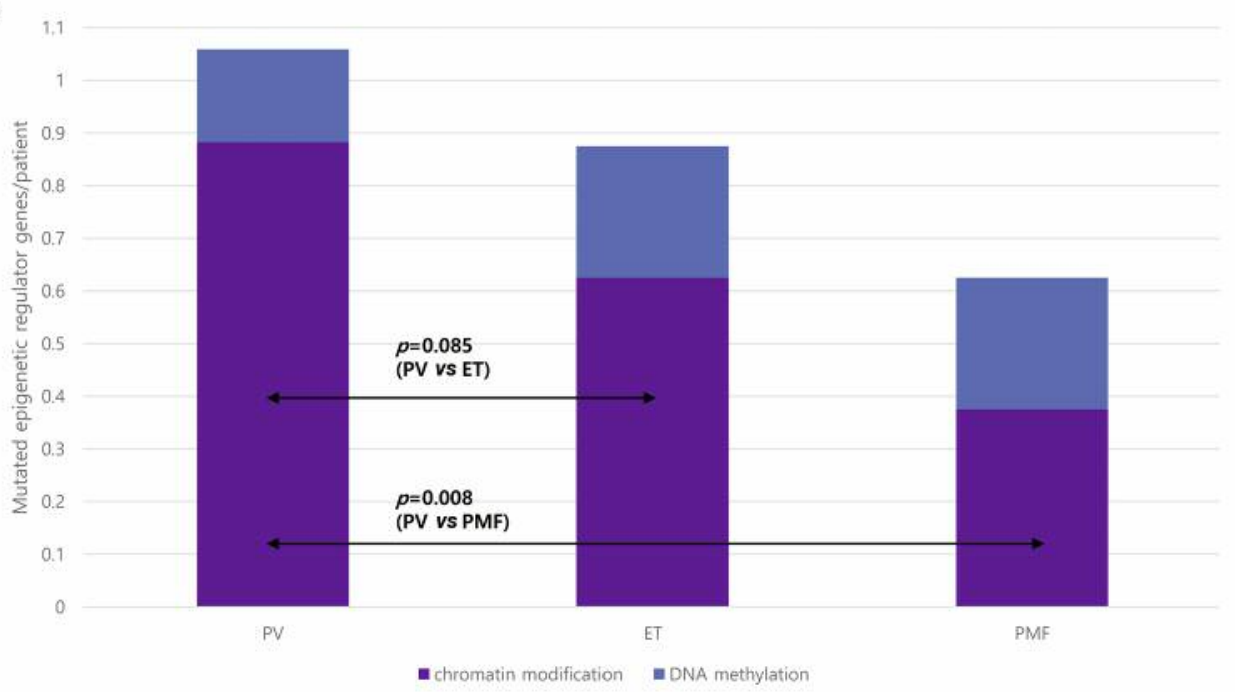

Figure 3. Subgroup specific mutation patterns. (A) Mutation frequency of splicing genes. (B) Mutation frequency of epigenetic regulator genes. Epigenetic regulator genes are subdivided.

On the other hand, mutations in epigenetic regulators were significantly more frequent in PV. Specifically, when epigenetic regulators were divided into chromatin modifiers and DNA methylators, there were no differences in DNA methylation gene mutations across MPN subgroups while PV patients harbored more mutations of genes involved in chromatin modification compared to ET $(p=0.085)$ and PMF $(p=0.008)$ (Figure 3B).

Among PV patients, those with ASXL1 mutation had significantly lower hemoglobin count at MPN diagnosis compared to those without $(15.2 \pm 1.8 \mathrm{~g} / \mathrm{dl} v s .18 .2 \pm 1.8 \mathrm{~g} / \mathrm{dl}$, $p=0.013$, Table II). These patients also had more thrombotic events compared to PV patients without $A S X L 1$ mutation $(p<0.001)$. More specifically, among ASXL1 mutated PV patients, 2 patients had cerebrovascular infarctions around the time of PV diagnosis, 1 had symptomatic portal vein thrombosis 2 years after diagnosis and 1 had past history of myocardial infarction. Overall, males harbored more ASXL1 mutations $(p=0.022)$.

Temporal sequence of mutations. When the temporal sequence of somatic mutation acquisition was considered, it appeared that PV patients acquired ASXL1 [mean variant allele frequency (VAF) 25.9\%] or EZH2 (VAF $31.5 \%$ ) mutations after $J A K 2 \mathrm{~V} 617 \mathrm{~F}$ mutation (mean VAF $55.6 \%$ for $A X L 1,50.8 \%$ for EZH2), while ET and PMF patients 


\section{Hematopoietic stem cells}

\section{MPN diagnosis}
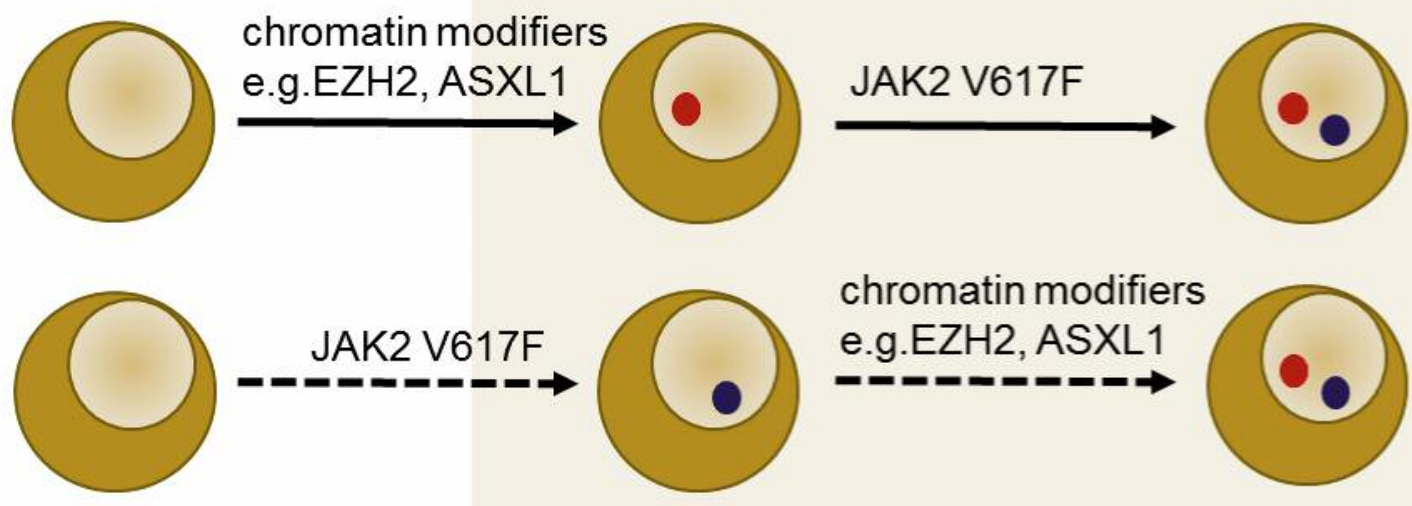

PV

Figure 4. Temporal sequence of mutation acquisition and clinical phenotypes.

Table II. Specific mutations and their clinical implications. (A) Additional splicing gene mutation acquisition in JAK2 positive primary myelofibrosis is associated with higher hemoglobin and platelet count at diagnosis. (B) Additional ASXL1 mutation in JAK2 positive polycythemia vera is associated with lower hemoglobin count at diagnosis. Data presented as mean ( \pm standard deviation).

\begin{tabular}{lccc}
\hline A & Splicing mutation & No splicing mutation & $p$-Value \\
\hline $\mathrm{Hb}(\mathrm{g} / \mathrm{dl})$ & $14.5(1.2)$ & $10.5(2.6)$ & 0.035 \\
$\mathrm{Plt}\left(10^{3} / \mu \mathrm{l}\right)$ & $717.2(275.6)$ & $260.5(248.4)$ & 0.049 \\
$\mathrm{WBC}\left(10^{3} / \mu \mathrm{l}\right)$ & $14.7(9.6)$ & $10.2(8.8)$ & 0.513 \\
\hline & & & \\
\hline $\mathrm{B}$ & ASXL1 mutated & No ASXL1 & $p$-Value \\
\hline $\mathrm{Plt}\left(10^{3 / \mu \mathrm{l})}\right.$ & $376.5(304.2)$ & $523.6(274.6)$ & 0.374 \\
$\mathrm{WBC}\left(10^{3} / \mu \mathrm{l}\right)$ & $25.6(28.3)$ & $12.7(4.0)$ & 0.431 \\
\hline
\end{tabular}

Hb, hemoglobin; Plt, platelet; WBC, white blood count.

acquired $A S X L 1$ (mean VAF $44.1 \%$ ) or $E Z H 2$ (VAF $41.5 \%$ ) mutations prior to $J A K 2$ V617F (mean VAF $26.1 \%$ for ASXL1, 28.4\% for EZH2) (Figure 4).

Prognostic implications of mutations. To analyze the clinical implications of mutations on prognosis, we first examined the impact of the number of mutations other than $J A K 2 V 617 F$ on survival and transformation and found that the number of somatic mutations did not play a significant role in the reduced overall survival (no additional mutations $v s$. one or more additional mutations, $p=0.440$ ) or increased risk of secondary transformation (no additional mutations $v s$. one or more additional mutations, $p=0.296)$. Next, we analyzed the role of JAK2 V617F allelic burden on survival and found that those with higher allele burden $(>50 \%)$ did not show propensity towards secondary transformation $(p=0.468)$. Males were associated with shorter overall survival $(p=0.042)$. When patients were analyzed per mutation, we observed that patients with TP53 mutation had shorter overall survival $(p=0.039$, Figure 5A). None of the patients harboring a TP53 mutation experienced secondary transformation, thus transformation-free survival was not analyzed. As shown in Figure 5B, splicing gene mutations were associated with reduced overall survival $(p=0.028)$ and increased risk of secondary transformation $(p=0.035)$. In addition, we found that patients with $A S X L 1$ mutation showed trends toward decreased overall survival ( $p=0.086$, Figure 5C) and significantly increased the risk of secondary transformation $(p=0.014$, Figure 5C).

Secondary transformations. The mutational landscapes of 7 patients who experienced secondary transformation are presented in Table III. Notably, 2 of the PMF patients harbored an ASXL1 mutation and one had a SRSF2 mutation. On the other hand, all the patients who transformed into sMF harbored at least one mutation in a tumor suppressor gene. 

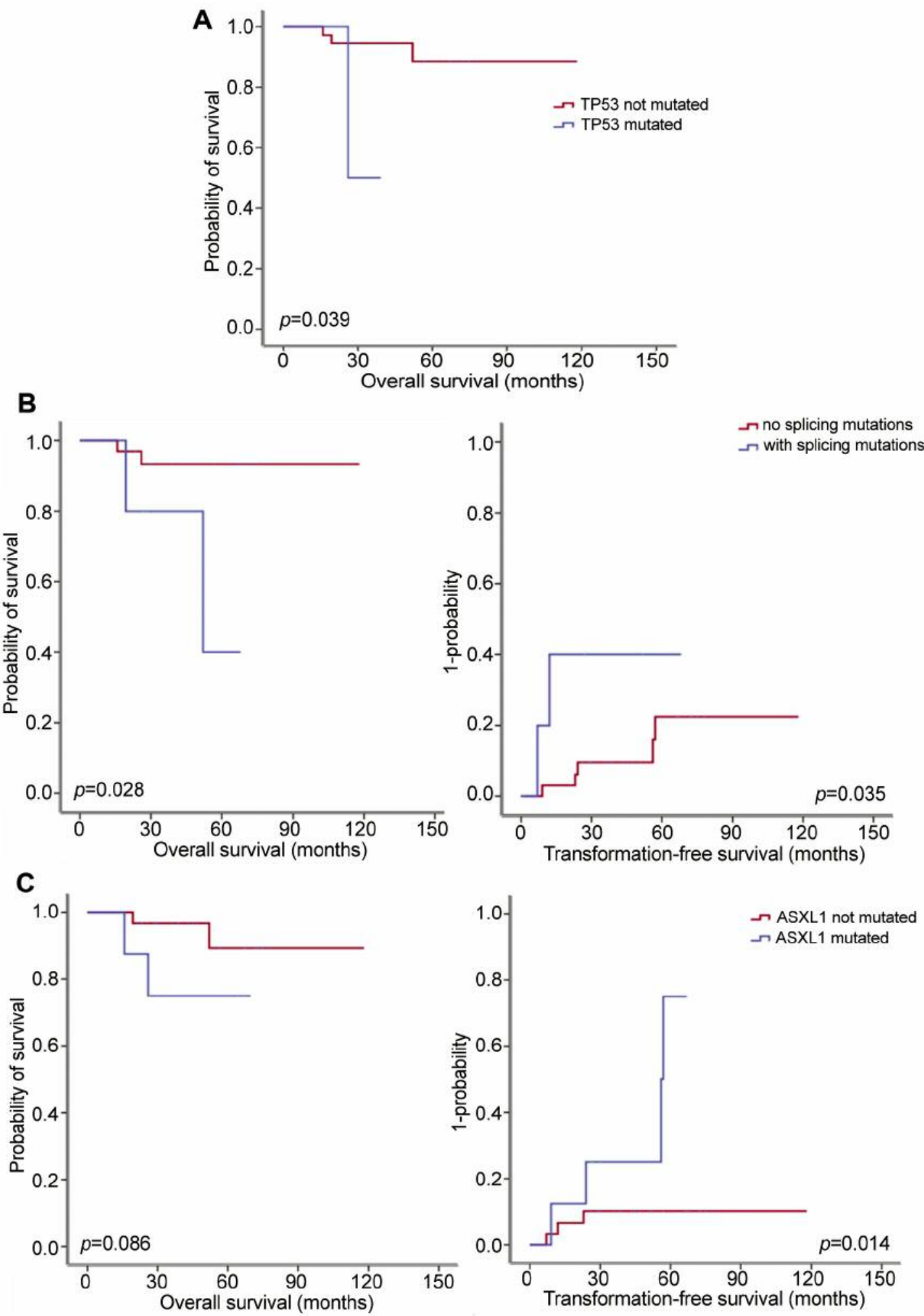

Figure 5. Survival curves stratified by the mutational status. (A) Overall survival between patients carrying TP53 mutations ( $n=2)$ versus patients without TP53 mutations $(n=39), p=0.039$. (B) Survival curves for patients with splicing mutations $(n=6)$ versus those without splicing mutations $(n=35)$. Left, overall survival $(p=0.028)$ and right, transformation free survival $(p=0.035)$. (C) Survival curves of patients carrying ASXL1 mutations $(n=8)$ versus patients without ASXL1 mutations $(n=33)$. Left, overall survival $(p=0.086)$ and right, transformation free survival $(p=0.014)$. 
Table III. The mutational landscape of the 7 patients experiencing secondary transformation.

\begin{tabular}{|c|c|c|c|c|c|c|c|c|c|c|c|c|c|c|c|}
\hline \multirow[t]{2}{*}{ MPN } & \multirow{2}{*}{$\begin{array}{l}\text { TFS } \\
(\mathrm{mo})\end{array}$} & \multirow[t]{2}{*}{ \# mut } & \multirow{2}{*}{$\begin{array}{l}\text { JAK2 } \\
\text { allele } \\
\text { burden }\end{array}$} & \multicolumn{8}{|c|}{ AML driver } & \multicolumn{4}{|c|}{ Tumor suppressor } \\
\hline & & & & ASXL1 & EZH2 & KMT2D & TET2 & SRSF2 & $\mathrm{U} 2 \mathrm{AF} 1$ & TP53 & NPM1 & FANCA & LRP1B & ARID2 & RB1 \\
\hline \multicolumn{16}{|c|}{ Secondary AML } \\
\hline PMF & 56 & 4 & 52 & 50 & & & & & & & & 47 & & & \\
\hline PMF & 9 & 3 & 9 & 49 & & & & & & & & & & & \\
\hline PMF & 12 & 3 & 71 & & & & & 39 & & & & & & & \\
\hline PV & 24 & 5 & 51 & 37 & 32 & & & & & 14 & & & & & \\
\hline \multicolumn{16}{|c|}{ Secondary MF } \\
\hline ET & 7 & 4 & 42 & & & 15 & 52 & & 27 & & & & & 50 & \\
\hline PV & 57 & 6 & 58 & 17 & & & 55 & & & & 19 & & 14 & & \\
\hline PV & 23 & 2 & 55 & & & & & & & & & & & & 50 \\
\hline
\end{tabular}

The numbers in each box represents allele burden in VAF. MPN: Myeloproliferative neoplasm; TFS: transformation free survival; mo: months; mut: mutation; AML: acute myeloid leukemia; PMF: primary myelofibrosis; PV: polycythemia vera; MF: myelofibrosis; ET: essential thrombocythemia.

\section{Discussion}

Several genes have been proposed as diagnostic or prognostic markers for MPN in the past few years (2-4). In this study we selected $J A K 2$ V617F positive patients to investigate the roles of somatic mutations other than the socalled driver mutations in MPN.

As expected, the $3 \mathrm{MPN}$ subgroups showed a different mutational spectrum at their chronic state. Notably, the group of analyzed splicing genes consisting of $U 2 A F 1, Z R S R 2$, $S R S F 2$, and $S F 3 B 1$ was most frequently mutated in PMF (Figure 3A), less frequently in ET, and none in PV. Mutations in genes involved in splicing are best known to be involved in myelodysplastic syndrome (MDS) pathogenesis $(9,10)$. MPN are known to share genetic mutations with MDS, but the reason for the phenotypic differences between these two disease entities remains unclear. Our findings suggest that PMF is more closely related to MDS than other MPN subgroups, which can also account for the higher risk of secondary leukemia in PMF compared to ET or/and PV. Also, possibly the triggering mutation at the hematopoietic stem cell level and the sequence of mutation acquisition may result in phenotypic differences. In previous studies, SRSF2 has been shown to play a role in secondary leukemia development from both MDS (11) and PMF (12). Aberrant function of mutated SRSF2 is associated with mis-splicing of multiple additional genes (e.g. RUNXI) that are implicated in the pathogenesis of AML (13). Likewise, one of the PMF patients experiencing secondary leukemia transformation in our cohort also harbored SRSF2 mutations (Table III). This again reinforces our suggestion that PMF is closely related to MDS, and the secondary leukemic transformations arising from PMF and MDS may share similar pathophysiology.

In the context of secondary leukemia transformation of PMF, another gene that deserves attention is ASXL1. Loss of function mutation of $A S X L 1$ results in loss of polycomb repressive complex 2 (PRC2)-mediated gene repression of known leukemogenic target genes (14). The possibility of non-overlapping contributions of $A S X L 1$ and JAK2 in myeloid transformation has been suggested by Abdel-Wahab et al. (15). Similarly, Vannucchi et al. (12) reported that leukemia-free survival was negatively impacted by ASXL1 mutation in PMF patients, while Engle et al. (16) showed expansion of ASXL1 clones upon transformation of PMF to secondary leukemia. Also, in our cohort, 2 of the 3 PMF patients experiencing secondary leukemia transformation harbored $A S X L 1$ mutation. Furthermore, ASXL1 mutations were associated with shorter transformation-free survival $(p=0.014$, Figure 3C). All in all, although the number of the patients harboring these mutations was small in our cohort, our results, nonetheless, support the role of $S R S F 2$ and ASXL1 in secondary leukemia transformation of PMF as has been shown in previous reports $(12,14-16)$.

Interestingly, the $J A K 2 V 617 F$ allele burden and the number of mutations per patient did not seem to play a role in the prognosis of patients. Whether JAK2 allele burden truly plays a role in the transformation of chronic MPN, and if so, the cutoff of JAK2 allele burden has been a debatable topic yet to be settled $(17,18)$. We used the cutoff of $50 \%$, and found that it did not play a role in transformation but we cannot draw a definitive conclusion because the number of transformed patients was too small and heterogeneous in nature. As for the number of mutations per patient and the lack of correlation to prognosis, careful interpretation is warranted as our results are based on targeted sequencing data of highly pre-selected genes rather than the whole genome or exome.

Although sMF occurs as part of the natural history of ET and $\mathrm{PV}$, with rates of transformation ranging from 5-10\% in ET and $10-15 \%$ in PV (19), MF transformation of MPN is 
somewhat less understood compared to acute leukemia transformation of MPN. A recent study from the AGIMM group (20) has shown that the molecular landscape of sMF is different from that of PMF and suggested that unknown mutational events might contribute to the disease progression. There were $3 \mathrm{sMF}$ patients in our cohort and except for the fact that all of them had mutations in tumor suppressor genes, there were no common grounds to establish a distinctive pattern.

The effect of the mutation order in MPN has been shown to alter clinical features and clonal evolution $(21,22)$. Focusing on ASXL1, EZH2 and JAK2, we found that ASXL1 or $E Z H 2$ mutation acquisition after $J A K 2$ leads to PV, while $A S X L 1$ mutation acquisition before JAK2 leads to ET or PMF (Figure 2). It is interesting to note that both ASXL1 and $E Z H 2$ are key regulators of PRC2, and are known to play a role in MPN initiation and disease progression (14). As such, the difference in temporal sequence of epigenetic regulators mutation acquisition may determine the phenotype of JAK2 positive MPN, and also explain the natural disease course of each MPN subtype. For example, as ASXL1 deletion is associated with defective hematopoietic stem cells selfrenewal properties leading to profound cytopenias and dysplasias, this sequence of mutations may explain why ET is more closely related to pre-fibrotic PMF. Our results alone are underpowered due to the small number of patients included, but taking into consideration that our findings are in agreement with a recent report from Grinfeld et al. (23) who showed that in ET JAK2 is commonly a secondary event while in PV it is an earlier event, we can hypothesize that these results are at least corroborative in nature and thus deserve scientific recognition.

Also, among PV patients, ASXL1 mutation was associated with lower hemoglobin, platelet and higher WBC count at $\mathrm{PV}$ diagnosis. This finding is in agreement with the recent report that $A S X L 1$ mutation is correlated with features of PMF, such as increased reticulin fibrosis and reduced myeloid erythroid ratio (24). Meanwhile, splicing genes mutated PMF were associated with higher hemoglobin, platelet and WBC count at PMF diagnosis. It would be interesting to see if these subgroups of patients represent masked PV and pre-fibrotic MF.

The obvious limitation of our study is the small number of patients included. Another pitfall of our study is the lack of sequential samples to actually track the clonal evolution at various stages of MPN clinical course trajectory. However, the value of our study lies in that it contains adequate scientific clues to inspire future studies regarding the genetic landscape of MPN. Given that our study mainly concerned East Asian patients, a larger scale study of a similar population should ensue for further corroboration of our results.

In conclusion, our findings provide a better understanding of JAK2 positive MPN and its genetic backgrounds. Although the scale is small, we also provide evidence that each subtype of MPN harbors distinct patterns of somatic mutations and acquisition order, and that mutations in TP53, ASXL1, and splicing genes may be associated with the prognosis of MPN.

\section{Conflicts of Interest}

There are no conflicts of interest to disclose regarding this study.

\section{Authors' Contributions}

Designed the study: Sung-Soo Yoon, Youngil Koh, Ja Min Byun. Patient enrollment and data collection: Ja Min Byun, Youngil Koh, Sung-Soo Yoon. Analyzed the data: Ja Min Byun, Seulki Song, Daeyoon Kim. Wrote the paper: Ja Min Byun, Seulki Song. Revised the paper: all the authors.

\section{Acknowledgements}

This research was supported by a grant funded by the Ministry of Health \& Welfare, Republic of Korea (grant number: NRF2017R1D1A1B03035151). The Authors would like to thank Dr. John E. Dick and the members of the John Dick Lab of Princess Margaret Cancer Centre, Toronto, Ontario, Canada for their advice and help in processing the data for this study. The abstract of this manuscript has been presented as a poster at the American Society of Hematology Annual Meeting, 2017, Atlanta.

\section{References}

1 Campbell PJ and Green AR: The myeloproliferative disorders. N Engl J Med 355: 2452-2466, 2006. PMID: 17151367. DOI: 10.1056/NEJMra063728

2 Kralovics R, Passamonti F, Buser AS, Teo SS, Tiedt R, Passweg JR, Tichelli A, Cazzola M and Skoda RC: A gain-of-function mutation of JAK2 in myeloproliferative disorders. N Engl J Med 352: 17791790, 2005. PMID: 15858187. DOI: 10.1056/NEJMoa051113

3 Tefferi A and Vainchenker W: Myeloproliferative neoplasms: molecular pathophysiology, essential clinical understanding, and treatment strategies. J Clin Oncol 29: 573-582, 2011. PMID: 21220604. DOI: $10.1200 /$ JCO.2010.29.8711

4 Kennedy JA, Atenafu EG, Messner HA, Craddock KJ, Brandwein JM, Lipton JH, Minden MD, Schimmer AD, Schuh AC, Yee KW and Gupta V: Treatment outcomes following leukemic transformation in Philadelphia-negative myeloproliferative neoplasms. Blood 121: 2725-2733, 2013. PMID: 23361905. DOI: $10.1182 /$ blood-2012-10-464248

$5 \mathrm{Li} \mathrm{H}$ and Durbin R: Fast and accurate long-read alignment with Burrows-Wheeler transform. Bioinformatics 26: 589-595, 2010. PMID: 20080505. DOI: 10.1093/bioinformatics/btp698

6 McKenna A, Hanna M, Banks E, Sivachenko A, Cibulskis K, Kernytsky A, Garimella K, Altshuler D, Gabriel S, Daly M and DePristo MA: The Genome Analysis Toolkit: a MapReduce framework for analyzing next-generation DNA sequencing data. Genome Res 20: 1297-1303, 2010. PMID: 20644199. DOI: 10.1101/gr.107524.110

7 Koboldt DC, Zhang Q, Larson DE, Shen D, McLellan MD, Lin L, Miller CA, Mardis ER, Ding L and Wilson RK: VarScan 2: 
somatic mutation and copy number alteration discovery in cancer by exome sequencing. Genome Res 22: 568-576, 2012. PMID: 22300766. DOI: 10.1101/gr.129684.111

8 Wang $\mathrm{K}, \mathrm{Li} \mathrm{M}$ and Hakonarson $\mathrm{H}$ : ANNOVAR: functional annotation of genetic variants from high-throughput sequencing data. Nucleic Acids Res 38: e164, 2010. PMID: 20601685. DOI: 10.1093/nar/gkq603

9 Yoshida K, Sanada M, Shiraishi Y, Nowak D, Nagata Y, Yamamoto R, Sato Y, Sato-Otsubo A, Kon A, Nagasaki M, Chalkidis G, Suzuki Y, Shiosaka M, Kawahata R, Yamaguchi T, Otsu M, Obara N, Sakata-Yanagimoto M, Ishiyama K, Mori H, Nolte F, Hofmann WK, Miyawaki S, Sugano S, Haferlach C, Koeffler HP, Shih LY, Haferlach T, Chiba S, Nakauchi H, Miyano S and Ogawa S: Frequent pathway mutations of splicing machinery in myelodysplasia. Nature 478: 64-69, 2011. PMID: 21909114. DOI: $10.1038 /$ nature 10496

10 Sperling AS, Gibson CJ and Ebert BL: The genetics of myelodysplastic syndrome: from clonal haematopoiesis to secondary leukaemia. Nat Rev Cancer 17: 5-19, 2017. PMID: 27834397. DOI: $10.1038 /$ nrc.2016.112

11 Kim T, Tyndel MS, Kim HJ, Ahn JS, Choi SH, Park HJ, Kim YK, Yang DH, Lee JJ, Jung SH, Kim SY, Min YH, Cheong JW, Sohn SK, Moon JH, Choi M, Lee M, Zhang Z and Kim DDH: The clonal origins of leukemic progression of myelodysplasia. Leukemia 31: 1928-1935, 2017. PMID: 28090092. DOI: 10.1038/leu.2017.17

12 Vannucchi AM, Lasho TL, Guglielmelli P, Biamonte F, Pardanani A, Pereira A, Finke C, Score J, Gangat N, Mannarelli C, Ketterling RP, Rotunno G, Knudson RA, Susini MC, Laborde RR, Spolverini A, Pancrazzi A, Pieri L, Manfredini R, Tagliafico E, Zini R, Jones A, Zoi K, Reiter A, Duncombe A, Pietra D, Rumi E, Cervantes F, Barosi G, Cazzola M, Cross NC and Tefferi A: Mutations and prognosis in primary myelofibrosis. Leukemia 27: 1861-1869, 2013. PMID: 23619563. DOI: 10.1038/leu.2013.119

13 Makishima H, Visconte V, Sakaguchi H, Jankowska AM, Abu Kar S, Jerez A, Przychodzen B, Bupathi M, Guinta K, Afable MG, Sekeres MA, Padgett RA, Tiu RV and Maciejewski JP: Mutations in the spliceosome machinery, a novel and ubiquitous pathway in leukemogenesis. Blood 119: 3203-3210, 2012. PMID: 22323480. DOI: 10.1182/blood-2011-12-399774

14 Abdel-Wahab O, Adli M, LaFave LM, Gao J, Hricik T, Shih AH, Pandey S, Patel JP, Chung YR, Koche R, Perna F, Zhao X, Taylor JE, Park CY, Carroll M, Melnick A, Nimer SD, Jaffe JD, Aifantis I, Bernstein BE and Levine RL: ASXL1 mutations promote myeloid transformation through loss of PRC2-mediated gene repression. Cancer Cell 22: 180-193, 2012. PMID: 22897849. DOI: $10.1016 /$ j.ccr.2012.06.032

15 Abdel-Wahab O, Manshouri T, Patel J, Harris K, Yao J, Hedvat C, Heguy A, Bueso-Ramos C, Kantarjian H, Levine RL and Verstovsek S: Genetic analysis of transforming events that convert chronic myeloproliferative neoplasms to leukemias. Cancer Res 70: 447-452, 2010. PMID: 20068184. DOI: 10.1158/0008-5472.CAN-09-3783

16 Engle EK, Fisher DA, Miller CA, McLellan MD, Fulton RS, Moore DM, Wilson RK, Ley TJ and Oh ST: Clonal evolution revealed by whole genome sequencing in a case of primary myelofibrosis transformed to secondary acute myeloid leukemia. Leukemia 29: 869-876, 2015. PMID: 25252869. DOI: 10.1038/leu.2014.289

17 Mesa RA, Verstovsek S, Cervantes F, Barosi G, Reilly JT, Dupriez B, Levine R, Le Bousse-Kerdiles MC, Wadleigh M,
Campbell PJ, Silver RT, Vannucchi AM, Deeg HJ, Gisslinger H, Thomas D, Odenike O, Solberg LA, Gotlib J, Hexner E, Nimer SD, Kantarjian H, Orazi A, Vardiman JW, Thiele J and Tefferi A; International Working Group for Myelofibrosis Research and Treatment (IWG-MRT): Primary myelofibrosis (PMF), post polycythemia vera myelofibrosis (post-PV MF), post essential thrombocythemia myelofibrosis (post-ET MF), blast phase PMF (PMF-BP): Consensus on terminology by the international working group for myelofibrosis research and treatment (IWGMRT). Leuk Res 31: 737-740, 2007. PMID: 17210175. DOI: 10.1016/j.leukres.2006.12.002

18 Rotunno G, Pacilli A, Artusi V, Rumi E, Maffioli M, Delaini F, Brogi G, Fanelli T, Pancrazzi A, Pietra D, Bernardis I, Belotti C, Pieri L, Sant'Antonio E, Salmoiraghi S, Cilloni D, Rambaldi A, Passamonti F, Barbui T, Manfredini R, Cazzola M, Tagliafico E, Vannucchi AM and Guglielmelli P: Epidemiology and clinical relevance of mutations in postpolycythemia vera and postessential thrombocythemia myelofibrosis: A study on 359 patients of the AGIMM group. Am J Hematol 91: 681-686, 2016. PMID: 27037840. DOI: 10.1002/ajh.24377

19 Tefferi A, Lasho TL, Huang J, Finke C, Mesa RA, Li CY, Wu W, Hanson CA and Pardanani A: Low JAK2V617F allele burden in primary myelofibrosis, compared to either a higher allele burden or unmutated status, is associated with inferior overall and leukemia-free survival: Leukemia 22: 756-761, 2008. PMID: 18216871. DOI: $10.1038 /$ sj.leu.2405097

20 Passamonti F and Rumi E: Clinical relevance of JAK2 mutant allele burden. Haematologica 94: 7-10, 2009. PMID: 19118374. DOI: $10.3324 /$ haematol.2008.001271

21 Ortmann CA, Kent DG, Nangalia J, Silber Y, Wedge DC, Grinfeld J, Baxter EJ, Massie CE, Papaemmanuil E, Menon S, Godfrey AL, Dimitropoulou D, Guglielmelli P, Bellosillo B, Besses C, Döhner K, Harrison CN, Vassiliou GS, Vannucchi A, Campbell PJ and Green AR: Effect of mutation order on myeloproliferative neoplasms. N Eng J Med 372: 601-612, 2015. PMID: 25671252. DOI: 10.1056/NEJMoa1412098

22 Lundberg P, Karow A, Nienhold R, Looser R, Hao-Shen H, Nissen I, Girsberger S, Lehmann T, Passweg J, Stern M, Beisel C, Kralovics R and Skoda RC: Clonal evolution and clinical correlates of somatic mutations in myeloproliferative neoplasms. Blood 123: 2220-2228, 2014. PMID: 24478400. DOI: 10.1182/blood-2013-11-537167

23 Grinfeld J, Nangalia J, Baxter EJ, Wedge DC, Angelopoulos N, Cantrill R, Godfrey AL, Papaemmanuil E, Gundem G, MacLean C, Cook J, O'Neil L, O'Meara S, Teague JW, Butler AP, Massie CE, Williams N, Nice FL, Andersen CL, Hasselbalch HC, Guglielmelli P, McMullin MF, Vannucchi AM, Harrison CN, Gerstung M, Green AR and Campbell PJ: Classification and personalized prognosis in myeloproliferative neoplasms. N Engl J Med 379: 1416-1430, 2018. PMID: 30304655. DOI: 10.1056/NEJMoa1716614

24 Wong WJ, Hasserjian RP, Pinkus GS, Breyfogle LJ, Mullally A and Pozdnyakova O: JAK2, CALR, MPL and ASXL1 mutational status correlates with distinct histological features in Philadelphia chromosome-negative myeloproliferative neoplasms. Haematologica 103: e63-e68, 2018. PMID: 29146710. DOI: 10.3324/haematol.2017.178988

Received September 23, 2019

Revised October 14, 2019

Accepted October 18, 2019 